\title{
English-Majored Students' Research Engagement: Research Areas, Limitations and Implications
}

\section{Cuong Huy Pham}

\section{Article History}

Received: 15 December 2020

Accepted: 26 February 2021

Published: 30 March 2021

\section{Keywords}

Students' research

engagement, research skills, research reports, higher education, English language

\author{
University of Economics and Law, Vietnam National University, Ho Chi \\ Minh City \\ Email: cuongph@uel.edu.vn
}

\section{INTRODUCTION}

Doing research has become one of the highly encouraged academic activities among English-majored students in universities across Vietnam. It aims to enrich their understanding of a particular linguistic area concerning their field of study. Such engagement also contributes to developing their academic writing and research skills as well as personal and interpersonal strategies in doing research. This facilitates their access to higher levels of education and sharpens the skills required for conducting independent research projects that they are likely to carry on in their future careers. However, students' research engagement is quite a challenging undertaking given the relatively limited opportunities for research activities within the curriculum, and the degree of interest and commitment that students demonstrate during this process. This article presents the common research areas that students opt for and the problems they encounter in writing research reports based on the analysis of prior research projects.

\section{LITERATURE REVIEW}

\subsection{Merits of students' research engagement}

Research is an important element contributing to changing the academic landscape in educational institutions around the world (Atweh \& Burton, 1995; Badke, 2012; Woeste, \& Barham, 2007). Despite its significance, doing research has been regarded as the sole responsibility of researchers and academic staff whose works function as primary generators of knowledge and as "the basis for decision-making in educational settings or solving problems in the lived experience of students" (Atweh \& Burton, 1995, p. 561). This practice partly downplays the voices of students who are direct beneficiaries of such knowledge. Students' research refers to any teaching and learning activities in which "undergraduate students are actively engaged with the research content, or processes and problems of their discipline" (Zimbardi \& Myatt, 2014, p. 234). This view covers a broad range of aspects contributing to sharpening their research skills including the identification of the research problem concerning their field of study, the research process as well as research writing. It also places a strong emphasis on students' proactive involvement in such processes. Indeed, there has been a substantial shift from this traditional view to seeing students as "transformative agents" (Kincheloe \& Steinberg, 2002a), thus 
highlighting the more central involvement of students in research and knowledge-formation processes. Students' research engagement is generally defined as "the energy and effort that students employ within their learning community, observable via any number of behavioral, cognitive or affective indicators across a continuum" (Bond et.al., 2020, p. 3). In other words, students' engagement in research activities is contingent on their level of enthusiasm and the amount of personal effort they expend to undertake their undergraduate studies and can be observed through various channels including their actions, ways of thinking and emotional expressions. In the present study, research engagement involves not only students' effort to fulfill their projects but also respond to the professional aspects of their chosen majors/minors and the research-related requirements stipulated by their institutions. Such commitment to research empowers them with "new ways of knowing and producing knowledge that challenge the common sense views of reality with which most individuals have grown so comfortable" (Kincheloe \& Steinberg, 2002a, p. 2). The value of this process is two-folded: not only are students able to develop critical reflection and evaluation of the issues concerning their learning but they also become the producers of knowledge. In this vein, Kincheloe and Steinberg (2002b, p. 240) argued that "As active inquirers, students no longer see themselves as the passive receivers of expert produced knowledge. They become responsible agents who engage in their own interpretations of the world around them". This changing perspective on students as researchers requires more attention to the role they perform in tackling educational problems as well as creates opportunities for their further research engagement.

\subsection{Limitations of students' research}

As the primary aim of students' research engagement is to provide them with the skills and knowledge for conducting independent projects as well as further exploration of their area of study, many issues may arise along the process (Zimbardi \& Myatt, 2014). This may be the first experience for most undergraduate students in undertaking research on an area of their academic interest but at the same time a challenging endeavor. In most cases, students are not expected to generate novel knowledge but rather provide an overview of the literature relevant to their fields of study or interests, or demonstrate certain understanding of the research procedures (Sharp, Peters \& Howard, 2002). However, they may exhibit many limitations during this process in relation to the choice of topic, students' use of research resources and their lack of familiarity with research culture. Firstly, opting for an appropriate research topic is of great importance as it guides the whole project and mediates the other elements throughout the engagement (Sharp, Peters \& Howard, 2002). One of the constraints on students' choice of topic is the short-term nature of their projects leading to the fact that "they do not have the personal investment in their topic or even the discipline that a professional in the field would have" (Burton \& Chadwick, 2000, p. 321). Furthermore, students have been reported to stick to textbooks as the main source of references for research (Burton \& Chadwick, 2000). This results in their failure to incorporate knowledge from wider sources that are highly accessible such as the library resources or online documents. Finally, students tend to conduct their research with very limited demonstration of knowledge of research norms including the criteria for evaluating sources, norms of citing and referencing, and the components of each section within their research reports (Carlson, 2006; Sharp, Peters \& Howard, 2002). Therefore, it is vital that the specific causes leading to these issues be identified to facilitate students' research engagement.

\subsection{Students' research in the context of Vietnamese higher education}

Universities in Vietnam have increasingly commenced to set their targets as research-oriented institutions for which they have endeavored to promote research among their academic staff and students (Hayden \& Phạm, 2010). To this end, students are introduced and familiarized with initial research elements within their academic program. These include integrating research components in certain undergraduate courses or encouraging students to form research teams. Some academically high achievers have the option of undertaking a formal research project as part of the requirements for their graduation. Also, there are a number of contests for student research from ministerial to municipal levels such as the annual ministerial student research awards (Bureau of Science, Technology and Environment, 2020), Euréka student research awards co-hosted by Vietnam National University of Ho Chi Minh City and Ho Chi Minh City Youth Union, and other university-based competitions. These activities contribute to a growing trend of fostering students' research engagement in higher education in Vietnam.

\section{RESEARCH METHODS AND RESULTS}

\subsection{Research methods}

\subsubsection{The research setting}

This study is conducted in the context of a private university based in Ho Chi Minh City, Vietnam where student research activities fall into two main categories: university-level research projects and independent small-scaled studies as a mandatory component in the curriculum. The former relies on students' voluntary participation and can 
be conducted individually, in pairs or in small groups. These research projects can be nominated for research competitions within the university and beyond. The latter is normally carried out in the students' final year in preparation for their university graduation. In both instances, students work with their own supervisor who is an experienced researcher and practitioner in the field of English language and linguistics to mediate their research process and inform the decisions they make in relation to their research.

3.1.2. Data collection and analysis

Drawing on convenience sampling, this study analyzed the data from 73 independent research reports conducted by English-majored students in the academic year of 2018-2019 to identify the research areas that were frequently chosen. Then, ten research reports (S1 - S10) were randomly selected by choosing every other seventh paper out of the 73 reports under investigation to pinpoint the common issues confronting the students in their research report writing.

Content analysis was adopted as the analytical frame within this study (Mayring, 2004). This approach is based on pre-formulated categories in order to classify data into different themes. Here, there are two major aspects of analysis: students' research directions and their limitations in writing research reports. For the former, each of the 73 research reports was carefully examined to identify which area of English language it fell into. The typical research areas derived from the data include language learning skills/strategies, English workplace, affective elements in language learning and teaching, language teaching methodology, translation issues, and other miscellaneous topics. The relevance of these research areas was then evaluated against the pre-prescribed minors of the English language major, namely Business English, English Language Teaching, and Translation and Interpreting. For the latter, the research guidelines issued by the Faculty of English where this study was conducted functioned as the criteria for analysis. The guidelines comprise the structure of a research report and the detailed description of how to write each section. Technical aspects of writing such as grammar, punctuation and use of academic style were also presented. Accordingly, each section of the ten chosen reports was scrutinized to determine the extent to which it responded to the guidelines as well as its alignment with contemporary literature on students' research limitations. Among the constraints emerging from the analysis of the research reports, four prominent areas were highlighted concerning students' identification of the research problem, utilization of references, approaches to analyzing prior research and their linguistic resources.

\subsection{Research results}

\subsubsection{Students' research directions}

Table 1 presents the students' chosen research areas for their final research projects. The research topics show relative diversity that falls within a number of sub-areas in linguistics and applied linguistics. The majority of the projects $(52.1 \%)$ focused on language learning skills and strategies for language learners at different levels from primary to tertiary education. This is significant as most of the students in this study took English language as their major and such choices of research areas demonstrate practical implications for their current studies and future careers. The second most popular research area centers on workplace English, accounting for 20.6\%. Other research directions are of low proportions including affective factors (9.6\%), language teaching techniques (6.8\%), issues concerning translation (6.8\%) and other minor aspects $(4.1 \%)$ such as English as a medium of instruction and using technology in language education.

Table 1. Percentages of students' chosen research areas $(N=73)$

\begin{tabular}{lcc}
\hline Chosen research areas & No. of research reports & Percentage \\
\hline Language learning skills/strategies & 38 & $52.1 \%$ \\
\hline Workplace English & 15 & $20.6 \%$ \\
\hline Affective factors (e.g. attitudes, motivation, agency) & 7 & $9.6 \%$ \\
\hline Language teaching techniques & 5 & $6.8 \%$ \\
\hline Translation issues & 5 & $6.8 \%$ \\
\hline Others (e.g. EMI, educational technology) & 3 & $4.1 \%$ \\
\hline
\end{tabular}

However, further mapping between the research areas that the students opted for and their corresponding minors in English language showed certain inconsistency. As indicated in Table 2, all the students doing English Language Teaching chose research topics directly related to their minor. Conversely, those studying Translation and Interpreting and Business English tended to divert significantly from their minors with the percentages of relevant research topics at $26.32 \%$ and $33.33 \%$ respectively. These students switched to working on topics related to English Language Teaching for their research reports. This practice impedes students' ability to apply the knowledge they learned in their minors in their research projects. As Erickson (2001, pp. 24-25) points out, the value of research is to enable students to determine a suitable career path, evaluate the relevance of their studies and follow their academic pursuit. The mismatch between students' research directions and their minors in the present study may drastically impact on their future employment as 
well as an upgrade to graduate education. It is therefore important that their supervisors draw their attention to such scenarios and guide them toward choosing a research area more closely related to their minor or research interests.

Table 2. The relevance of students' research topics to their minors

\begin{tabular}{lccc}
\hline Minors in English language & $\begin{array}{c}\text { No. of } \\
\text { research reports }\end{array}$ & $\begin{array}{c}\text { No. of } \\
\text { relevant topics }\end{array}$ & Percentage \\
\hline Translation and Interpreting & 19 & 5 & $26.32 \%$ \\
\hline Business English & 39 & 13 & $33.33 \%$ \\
\hline English Language Teaching & 15 & 15 & $100 \%$ \\
\hline
\end{tabular}

3.2.2. Limitations in students' research report writing

This section illustrates the constraints that the students encountered in writing their research reports based on the analysis of ten randomly selected research reports.

3.2.2.1. Statements of the research problem

Students' identification of the research problem tends to be of an intuitive nature presented in the form of personal claims with little or even no support from relevant literature. This is evident in the following statement of the research problem on the challenges of developing speaking skills:

To learn and to use English well, learners are supposed to be good at four skills: listening, speaking, reading and writing. All of them are interrelated from another one. Speaking is one of the most expected skills because it helps learners to express their idea, their emotion. Therefore, when learning English, people have to learn how to speak effectively. (S8)

Another problem is related to the rigor of the arguments showcasing the rationale for carrying out the research as in the following:

Nowadays, with high development of technology, especially smartphone, people unintentionally ignore book, a useful and informative partner for their lives. Throughout the day, they only pay attention on their phone surfing social networks, playing games, chatting and taking selfie instead of spending time learning new things such as reading books. For those who want to become a professional translator or interpreter, it is essential for them to read not only Vietnamese books but also English books. (S1)

In both instances, the students failed to provide contextual or empirical evidence to substantiate their reasons for undertaking their research topics. Such an approach to addressing the research problem also reveals the students' limited ability to present the rationale behind their projects in a convincing manner, thus overlooking an important feature of students' research as "an active learning process" that "challenges students to frame questions, develop a strategy for testing their propositions, ... [and] learn to support an argument” (Erickson, 2001, p. 25).

3.2.2.2. Diversity and relevance of references

Citing and quoting other research are an important dimension of writing research reports and require students to master the norms of referencing as well as adopt proper citing behaviors (Carlson, 2006). Students are expected not only to adhere to appropriate citing and referencing formats but also vary the text types, e.g. books, journal articles, and theses, discussed in the reports and evaluate the relevance of the sources cited (Burton \& Chadwick, 2000; Sharp, Peters \& Howard, 2002). The diversity and relevance of the references are the two prominent issues confronting the students in the present study.

In a project on identifying common mistakes that secretaries usually make in writing business emails, S10 referred to a total of twelve different sources. However, all of them are of the same text types, i.e. webpages, which is not only problematic in terms of the reliability of the sources but also restricts the diversity of perspectives and insights that substantiate the statements made by the students.

Another issue arising from the choice of references is the relevance of the publications cited. Although all the ten research projects were situated in the context of Vietnam, only two of them reviewed one or two studies conducted locally but rather loosely connected to their research topics. This points the limitations in terms of showcasing elements in the local contexts embracing their studies.

3.2.2.3. Lack of a critical approach to literature review

Developing a critical approach to reviewing the literature is a formidable barrier to novice researchers (Steinberg \& Kincheloe, 2002). Analyses of the literature review of the ten reports in this study show that most of the students tended to describe or list rather than critically evaluate the research cited. They fail to address the connections among the arguments made by different authors as in the following excerpts: 
Excerpt 1: This excerpt concerns the definitions of listening comprehension from a study that investigates the factors affecting learners' listening comprehension.

The term "listening comprehension" has been defined by different authors. Mendelsohn (1994) defines listening comprehension as - the ability to understand the spoken language of native speakers. Rost (2002) and Hamouda (2013) defined listening comprehension as an interactive process in which listeners are involved in constructing meaning. Dirven and Oakeshott-Taylor (1984) defined listening comprehension as the product of teaching methodology and is matched by terms such as speech understanding, spoken language understanding, speech recognition, and speech perception. According to Brown and Yule (1983), listening comprehension means that a person understands what he/she has heard. If he/she learns the text through hearing it, he/she will understand it. Another definition of listening comprehension is to understand what a speaker says (Anderson \& Lynch, 1988). (S7)

Excerpt 2: This excerpt elaborates on extensive reading from a study on learners' challenges in reading comprehension.

In extensive reading, the readers usually face with a long text. In reading, the students need a total understanding with the meanings of the author. According to Brown (2001), extensive reading is carried out to achieve a general understanding of a text. Long and Richards (1987) identify extensive reading as occurring when the students read large amounts of high interest material, concentrating of meaning, reading for gist and skips unknown the words. (S6)

In these excerpts, the definitions of key terms were listed, showing the students' lack of the ability to critically evaluate the strengths and weaknesses of each source and the alignment between the sources. This way of writing also failed to point to the definition(s) underpinning the students' research. The students were also unable to compare and contrast theoretical perspectives underpinning their studies. These findings contradict those in Zimbardi and Myatt's (2014, p. 238) study whereby the participants felt a strong need to "interact critically with this literature to develop their research projects."

3.2.2.4. Students' limited linguistic resources

Most of the research reports show typical problems with students' use of language, particularly word choice (WC), grammar (GM), structure (ST) and academic styles (AS). These errors are underlined in the following excerpts from the implications of one of the studies:

According to many studies, anxiety is a critical problem that needs to get rid of as soon as possible (GM, AS). Students tend to scare (GM) of how people will look down on (AS) them when they make mistake (GM). To overcome this, they should relax to make themselves comfortable first. Do not care too much $(A S)$ how people will react because it is life (AS), some loves you and some hates you (GM \& ST). If this does not work on (GM) them, they should go find (WC \& AS) mental doctor (GM) to cure the illness (WC). (S3)

Another excerpt from an abstract that exhibits similar constraints:

The fact that, for many decades, there are many adults who learn English, because they want a new job better, or simply to travel abroad (GM, ST \& AS). This study aims to explore the challenges and problems of adults learning English. Thereby giving solutions to these problems (ST). (S2)

It is evident from the two texts that the students needed further practice on technical aspects of writing and pay closer attention to the academic style. These limitations could be remedied through careful proofreading conducted by the students themselves or their peers, or eliciting support from their supervisors.

\section{DISCUSSION AND CONCLUSION}

This study provides insights into the areas that English-majored students opted for their research projects and the issues confronting them in writing research reports. Despite such limitations, the students demonstrated huge potential for doing research as well as their relative understanding of the minors in English language. Erickson (2001) notes that "research experience has been credited with improving students' motivation for learning. Students can pursue their individual interests. Intellectual curiosity is sparked, and research provides undergraduates with an opportunity to take greater ownership of their own learning process." University stakeholders, particularly potential supervisors, can facilitate their research process in a number of ways. There should be more research-related components within the English language curriculum and step-by-step development of students' research skills throughout their academic program. Curriculum and syllabus designers also need to seriously consider these elements as a way to empower students with research skills and the motivation to undertake independent research projects in a more confident manner. This contributes to not only enhancing the quality of student research but also promoting an inquiry-based language learning environment which has been proven to be highly conducive to learning (Mieg, 2017). It would also be useful to organize regular seminars as platforms for researchers, teachers and students to share their research experience, resolve their shortcomings as well as raise students' awareness of the value of doing research. Furthermore, the university could consider offering more academic as well as financial 
incentives for research activities among students. For potential supervisors of undergraduate research projects, developing understanding of students' challenges and limitations in doing research could facilitate their supervision process. This could be achieved by having frequent communication and discussion with students through which they are able to analyze students' strengths, linguistic interests and career orientations in order to guide them toward appropriate areas for their research projects. Teachers and students can also form research partnerships as opportunities for mutual learning (Maunder et al., 2012). This allows teachers to reflect their language teaching and research practice from the perspective of students who are also involved in the research process. At the same time, students can sharpen their research skills and insights into the chosen areas through the mediation of teachers.

\section{REFERENCES}

Atweh, B., \& Burton, L. (1995). Students as researchers: Rationale and critique. British Educational Research Journal, 21(5), 561-575. doi:10.1080/0141192950210502

Badke, W. B. (2012). Teaching research processes: The faculty role in the development of skilled student research. Oxford: Chandos Publishing.

Bond, M., Buntins, K., Bedenlier, S., Zawacki-Richter, O., \& Kerres, M. (2020). Mapping research in student engagement and educational technology in higher education: a systematic evidence map. International Journal of Educational Technology in Higher Education, 17(2). doi:10.1186/s41239-019-0176-8

Bureau of Science, Technology and Environment (2020). Student research awards of 2020. Vietnam Ministry of Education and Training. Retrieved from https://moet.gov.vn/tintuc/Pages/tin-tong-hop.aspx?ItemID=7003

Burton, V. T., \& Chadwick, S. A. (2000). Investigating the practices of student researchers: patterns of use and criteria for use of internet and library sources. Computers and Composition, 17(3), 309-328. doi:10.1016/s87554615(00)00037-2

Carlson, J. (2006). An examination of undergraduate student citation behavior. The Journal of Academic Librarianship, 32(1), 14-22. doi:10.1016/j.acalib.2005.10.001

Erickson, R. A. (2001). Why involve students in research? Innovations in Undergraduate Research and Honors Education: Proceedings of the Second Schreyer National Conference. https://digitalcommons.unl.edu/nchcschreyer2/10

Hayden, M., \& Pham, N. T. (2010). Vietnam's higher education system. In G. Harman, M. Hayden, \& N. T. Pham (Eds.), Reforming higher education in Vietnam: Challenges and priorities (pp. 15-30). New York: Springer.

Kincheloe, J. L., \& Steinberg, S. R. (2002a). Students as researchers: Critical visions, emancipatory insights. In S. R. Steinberg \& K. L. Kincheloe (Eds), Students as researchers: Creating classrooms that matter (pp. 2-19). Bristol: Taylor \& Francis.

Kincheloe, J. L., \& Steinberg, S. R. (2002b). Making meaning and analyzing experience - student researchers as transformative agents. In S. R. Steinberg \& K. L. Kincheloe (Eds), Students as researchers: Creating classrooms that matter (pp. 228-246). Bristol: Taylor \& Francis.

Maunder, R. E., Cunliffe, M., Galvin, J., Mjali, S., \& Rogers, J. (2012). Listening to student voices: Student researchers exploring undergraduate experiences of university transition. Higher Education, 66(2), 139-152. doi:10.1007/s10734-012-9595-3

Mayring, P. (2004). Qualitative content analysis. In U. Flick, E. v. Kardorff, \& I. Steinke (Eds.). A companion to qualitative research (pp. 266-269). Thousand Oaks: Sage.

Mieg, H. A. (Ed.) (2017). Inquiry-based learning - undergraduate research: The German multidisciplinary experience. Berlin, Germany: Springer Open.

Sharp, J. A., Peters, J., \& Howard, K. (2002). The management of a student research project ( $3^{\text {rd }}$ ed.). Burlington: Gower.

Steinberg, S. R., \& Kincheloe, K. L. (Eds). (2002). Students as researchers: Creating classrooms that matter. Bristol: Taylor \& Francis.

Woeste, L. A., \& Barham, B. J. (2007). Undergraduate student researchers, preferred learning styles, and basic science research: A winning combination. The Clearing House: A Journal of Educational Strategies, Issues and Ideas, 81(2), 63-66. doi:10.3200/tchs.81.2.63-66

Zimbardi, K., \& Myatt, P. (2014). Embedding undergraduate research experiences within the curriculum: a crossdisciplinary study of the key characteristics guiding implementation. Studies in Higher Education, 39, 233-250. doi:10.1080/03075079.2011.651448 